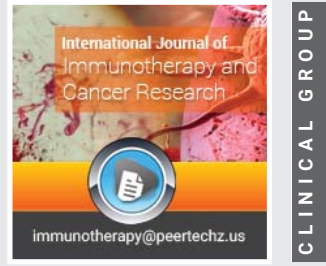

\title{
Tumor-associated
}

\section{macrophages: Shifting bad prognosis to improved efficacy in cancer therapies?}

\author{
Guillaume Harlé ${ }^{1 \#}$, Janske Nel ${ }^{1,2 \#}$, Camille Corbier $^{1 \#}$, Nadège \\ Touche $^{1}$ and Stéphanie Grandemange ${ }^{1 *}$ \\ 'Université de Lorraine and CNRS, CRAN UMR 7039, F-5400 Nancy, France \\ 2Université de Lorraine, Laboratoire Ingénierie des Biomolécules (LIBio), TSA 40602, Vandœuvre-lès- \\ Nancy, F-54518, France \\ \#Contributed Equally to this Manuscript
}

Received: 12 March, 2021
Accepted: 11 May, 2021
Published: 15 May, 2021

*Corresponding authors: Stéphanie Grandemange, Université de Lorraine and CNRS, CRAN UMR 7039, F-5400 Nancy, France, E-mail: stephanie.grandemange@univ-lorraine.fr

ORCID: https://orcid.org/0000-0002-4101-6303

Keywords: Cancer; Tumor-associated macrophages; Therapy resistance; Radio-resistance; Re-educated TAMs

https://www.peertechzpublications.com

\section{Check for updates}

\section{Abstract \\ Macrophages are innate immune cells that play an important role in the response to damaged tissue and pathogenic infection. During activation, signals from the local environment induce macrophage polarization towards either the classical pro-inflammatory phenotype (M1) or towards the alternative anti-inflammatory phenotype (M2). In cancer, M2 tumor-associated macrophages (TAMs) are associated with a poor prognosis. Notably, the Tumor Microenvironment (TME) is known to promote the M2 phenotype by dampening anti-tumor immune responses and thus promoting tumoral growth. Recent studies have demonstrated that TAMs play a major role in cancer cells resistance to chemo- and radiotherapies leading to ineffective treatment strategies. This raises the importance of including macrophage targeting strategies, either to dampen their activities or to re-educate them toward pro-inflammatory phenotype, to improve the efficiency of current and future treatments. Therefore, this mini- review aims to highlight recent discoveries demonstrating how macrophages induce cancer resistance to therapies and how re-educated TAMs could be used to improve treatment outcomes.}

\section{Abbreviations}

5-FU: 5-Fluorouracile; C/EBP:CCAAT-Enhancer Binding Proteins; CAR: Chimeric Antigen Receptor; CCL-C-C: Chemokine Ligand; CD: Cluster of Differentiation; CSF1: Colony Stimulating Factor 1; CXCR2-C-X-C: Chemokine Receptor Type 2; DAMPs: Damage-Associated Molecular Patterns; ER $\alpha$ :Estrogen Receptor Alpha; ICB: Immune Checkpoint Blockade; IFN $\gamma$ : Interferon-Gamma; IL: Interleukin; IRF: Interferon Regulatory Factor; LPS: Lipopolysaccharide; Mo: Macrophage-naïve macrophage; M1: Macrophage-classically activated macrophage; M2: Macrophage-alternatively activated macrophage; MAPK: Mitogen-Activated Protein Kinases; MHC-II: Major Histocompatibility Complex Type 2; miRNA: microRNA; mRNAs: messenger RNAs; PAMPs: Pathogen-Associated Molecular Patterns; PD-L1: Programmed Death Ligand 1; PI3K $\gamma$ : Phosphoinositide 3-kinase Gamma;
PRRs: Pattern Recognition Receptors; PTEN: Phosphatase and Tensin Homolog; ROS: Reactive Oxygen Species; SIRP: Signal Regulatory Protein Alpha; SOCS3: Suppressor of Cytokine Signaling 3 Gene; STAT3: Signal Transducer and activator of transcription 3; TAMs-Tumor Associated Macrophages; TGF- $\beta$ : Tumor Growth Factor Beta; Th: T Helper Cell; TLR: Toll-Like Receptor; TME: Tumor Microenvironment; TNF- $\alpha$-Tumor Necrosis Factor Alpha; VEGFs: Vascular Epithelial Growth Factors; VISTA: V-Domain Ig Suppressor of T cell Activation

\section{Introduction}

Macrophages are hematopoietic cells derived from myeloid precursors in bone marrow, and play a major role in resolving pathogenic infections by recognizing Pathogen-Associated Molecular Patterns (PAMPs) via Pattern Recognition Receptors (PRRs) [1,2]. Once activated, naive macrophages (Mo) are polarized into two main subsets; M1 or M2 [3-5]. 
M1 macrophage polarization (often referred to as classically activated macrophages) is induced by $\mathrm{Th} 1 \mathrm{CD}_{4}{ }^{+}$cells producing cytokines such as Interferon-Gamma (IFN $\gamma$ ) and tumor necrosis factor alpha (TNF- $\alpha$ ), or by toll-like receptor (TLR) activation [6-9]. For example, lipopolysaccharide (LPS) stimulation induces M1 polarization through the activation of TLR4 [9]. Once polarized towards the M1 subset, macrophages acquire a pro-inflammatory phenotype often associated with a high production of interleukin-1 (IL-1) and TNF- $\alpha$ [10]. Moreover, these cells exhibit an increased expression of major histocompatibility complex type II (MHC-II) and the costimulatory molecules $\mathrm{CD} 80 / 86$ which are associated with an enhanced ability for presenting antigens [11]. Conversely, M2 macrophage polarization (often referred to as alternatively activated macrophages) occurs under Th2 cytokines via IL-4, IL-10, IL-13 or tumor growth factor-beta (TGF- $\beta$ ) cytokines [12]. M2 macrophages exhibit an anti-inflammatory phenotype and are associated with a lower expression of MHCII and CD80/86 but a higher expression of CD206 (a mannose receptor). This subset produces anti-inflammatory cytokines such as IL-10 and TGF- $\beta$ known to dampen the immune cell response [12]. The M2 macrophage subset is mainly implicated in tissue repair processes (e.g., by boosting angiogenesis via the production of Vascular Epithelial Growth Factors (VEGFs)) and immune tolerance thus promoting a decline in local inflammation [13]. Regarding their phagocytic capacity, both M1 and M2 are more efficient than Mo macrophages [8], but M1 exhibits higher phagocytosis activity compared to M2 $[8,14]$. This duality and complex balance of M1 and M2 macrophage activation is crucial in several pathological conditions, including cancer.

In this mini-review, we provide an update of recent advances regarding the role of macrophages in cancer progression and the acquisition of resistance to therapeutic strategies focusing mainly on chemo-, hormone- and radiotherapies.

\section{Macrophages and their role in cancer development}

The role of macrophages during solid tumor development has been largely described $[15,16]$. Thus, in this section, we will briefly discuss the role of tumor-associated macrophages (TAMs), the main mechanisms for their polarization within tumors, and how this polarization impacts tumoral growth or regression.

Macrophages represent the most important leukocyte population to infiltrate the tumor tissue. Once in the tumor, macrophages have a dual role depending on their polarization. In general, it is accepted that the pro-inflammatory M1polarized phenotype promote an anti-tumor immune response whilst the anti-inflammatory properties of $\mathrm{M} 2$-polarized macrophages are associated with pro-tumor functions by dampening immune system responses and promoting metastasis in solid tumors [17-19]. M2 macrophages induce tumor cell proliferation and angiogenesis by producing growth factors that drive metastatic dissemination and tumoral growth [17]. Moreover, M2 macrophages produce TGF- $\beta$ and IL-10 cytokines known to dampen immune cells activation, consequently inhibiting anti-tumoral immune responses
[20]. When recruited to the Tumor Microenvironment (TME), the mature macrophages are converted into tumor associated macrophages referred to as TAM. The TME is known to predominantly polarize TAMs towards the M2 phenotype with a small fraction of $\mathrm{M} 1[21,22]$. In addition to enhancing the polarization towards pro-tumoral M2 macrophages, cancer cells also develop mechanisms to escape the immune system. As an example, cancer cells can overexpress the marker CD47 on their cell surface, and the interaction between $\mathrm{CD} 47$ and the receptor Signal-Regulatory Protein Alpha (SIRP $\alpha$ ) dampens phagocytosis activities, leading to cancer cell ignorance by macrophages [23].

Macrophages, cancer cells, and their surrounding stroma interact in a reciprocal manner. Cancer cells have been described to release vesicles and exosomes containing proteins and nucleic acids, such as microRNAs (miRNA) able to impact macrophage polarization $[24,25]$. Several studies have demonstrated the role of miRNAs, released by cancer cells, in inducing macrophages polarization [26-28]. For example, ovarian epithelial cancer cells express and release the miR222-3p which, once transferred to macrophages, induces M2 polarization by inhibiting the Suppressor of Cytokine Signaling 3 gene $\left(\mathrm{SOCS}_{3}\right)$ [29]. A decrease of SOCS3 expression in macrophages leads to a sustained activation of signal transducer and activator of transcription 3 (STAT3) which drives macrophage polarization toward the M2 phenotype [30]. Likewise, in colorectal cancer cells, exosomes-derived miR1246 promotes the expression of markers such as CD206 and CD163 thus inducing M2 polarization [31].

TAMs with an M1 pro-inflammatory phenotype tend to correlate with a favorable prognosis and longer survival for patients, whilst an increased accumulation of TAMs with an M2 anti-inflammatory phenotype in tumor tissue is now commonly associated with worse patient outcomes for several tumor types, including; glioma, head and neck, lung, pancreatic, breast, ovarian, colorectal, liver, melanoma, and bladder cancer [32-42]. It has thus become increasingly apparent that the role of TAMs in current treatment modalities, such as chemo- and radiotherapy, must be considered to have therapeutic implications and could be deemed a potential target for treatment strategies.

\section{Involvement of TAMs in cancer therapy resistance}

The M2 phenotype TAM association with bad prognoses is not only restricted to their ability to dampen the antitumor immune response and promote cancer cell proliferation and metastasis, but also to induce resistance to therapies by decreasing the efficacy of current treatment strategies. Here, we describe several recent studies describing how TAMs have hindered therapeutic strategies in different types of cancers by providing resistance to chemo-, hormone and radio-therapies.

\section{Role of TAMs in chemo- and hormonotherapy resis- tance}

Acquired resistance of cancer cells has been related to the ability of TAMs to secrete different factors such as cytokines, nucleotides or miRNAs. Recent studies have demonstrated 
that macrophages produce and release miRNAs that modulate the TME and, consequently, cancer cell sensitivity towards treatment. For example, a study by Zhu et al. showcased that TAMs produced exosomes enriched with miR-223 which could be transferred to ovarian epithelial cancer cells [43]. By transferring miR-223, macrophages are able to downregulate the phosphatase and tensin homolog (PTEN) protein expression in ovarian cancer cells, thus promoting PI3K/Akt signaling pathway known to play a role in cancer cell survival and provide cisplatin resistance [43].

TAMs in colorectal tumors have been demonstrated to exhibit low levels of cellular miR-155, which is known to decrease Janus kinase (JAK)2/STAT3 phosphorylation, leading to increased IL-6 production by macrophages [44]. Macrophage-derived IL- 6 activates the IL- 6 receptor (IL6R)/STAT3 pathway in cancer cells which downregulates miR-204 expression $[45,46]$. MiR-204 is known to dampen Bcl-2 and RAB22A gene expression leading to a decrease in the proliferation rate of cancer cells [47,48]. Therefore, by downregulating miR-204 in cancer cells, IL- 6 produced by macrophages promotes cancer cell proliferation and provides resistance to 5-fluorouracile (5-FU) therapy [44,48]. IL-6 production by TAMs induces STAT3 activation in ovarian cancers and decreased miR-204 levels leading to cisplatin resistance [49]. Moreover, macrophages-derived IL-6 also promotes the activation of the Hedgehog pathway in breast cancer cells dampening chemotherapy efficiency [50].

TAMs, polarized to the M2 phenotype, are known to produce TGF- $\beta$ and IL-10 [12]. Recent studies have demonstrated that the production of IL-10 by TAMs provides resistance to paclitaxel and carboplatin in breast cancer [51]. A study by Wei, et al. revealed that, in colorectal cancer, TAMs express a high level of C-C Chemokine Ligand 22 (CCL22) which activates the PI3K/Akt pathway in cancer cells and consequently decreases the pro-apoptotic effect of 5-FU [52]. Similarly, the secretion of CCL2 by TAM has also been linked to PI3K/Akt activation in tamoxifen resistant breast cancer cells [53]. Moreover, TAMs have been reported to contribute to tamoxifen and paclitaxel resistance in breast cancer either by interfering with the nuclear factor kappa-light-chain-enhancer of activated B cells (NF$\kappa B)$ pathway or chemotherapy-induced DNA damages. TAMs induce tamoxifen resistance by activating the NF- $\kappa B$ pathway leading to a hyperphosphorylation of Estrogen Receptor Alpha $(E R \alpha)$ independently from the presence of the ligand which promotes proliferation, migration and invasiveness of ER+ breast cancer cell lines [54]. Olson, et al. have demonstrated that TAMs are able to dampen the effects of paclitaxel on breast cancer cells by decreasing DNA damage and caspase activation thus dampening apoptosis induction [55]. Although the exact mechanism is not well understood, the resistance is hypothesized to be cell-contact independent and instead seems to be related to the secretome of TAMs which affects multiple signaling pathways. Another recent study demonstrated TAMs secreting nucleosides as the induction of pancreatic cancer cell resistance to gemcitabine [56]. Gemcitabine is a deoxycytidine analog which, upon incorporated into the DNA during replication, leads to cell death [57]. In this work, the authors observed that deoxycytidine release from TAMs can lead to gemcitabine resistance of pancreatic cancer cells [56].

\section{Role of TAMs in radiotherapy resistance}

Radiation therapy has been shown to induce Immunogenic Cell Death (ICD) wherein the release of tumor antigens, at the radiation site, induces immune responses. This leads to the accumulation of myeloid cells, the release of inflammatory cytokines (e.g. IL-1), monocyte/macrophage recruitment factors (e.g. IL-34 and colony-stimulating factor 1, CSF1), and pro-fibrotic mediators (e.g. TGF- $\beta$ ) [58]. ICD induction has been shown to contribute to anti-tumor immunity and has been seen as a promising exploitable process for cancer treatments. Unfortunately, downstream components of the immune system, such as TAMs, have been shown to either promote or suppress ICD.

Fractionated radiation therapy is considered to be immunosuppressive, stimulating the innate immune system towards a tissue repair response which promotes tumor recurrence and progression [59-62]. Macrophages have historically been noted to be relatively radioresistant, and are considered to be activated and recruited to play central roles as both the tumor-resident population of phagocytes and the central cells directing wound healing and tissue repair in tumoral tissues following radiation [63-65]. The macrophages which survive the radiation, and the recruited macrophages after, display a pro-tumoral M2 macrophage phenotype with enhanced pro-survival and pro-angiogenic activities often leading to tumor recurrence and treatment failure [66].

Interestingly, this immunomodulatory effect has been detected in distant tumors outside the field of the radiation treatment and is referred to as the abscopal effect, and highlights the importance of considering the immunological effects of ionizing radiation [67]. Notably, irradiation alone does not directly affect the production of effector molecules or cytokines in M1 or M2-activated macrophages but rather acts as an enhancer or inhibitor of inflammatory mediators $[68,69]$. Another important aspect regarding irradiation efficacy is hypoxia which can be compounded by TAMs as they can help modulate tumoral metabolism involved in aerobic glycolysis thus hindering the efficacy of radiotherapy [70].

The cascade of events regarding immunogenic cell death is orchestrated by several factors, of which Reactive Oxygen Species (ROS) have been implicated to play a role in the recruitment of monocytes and macrophage polarization. Depending on the environment, ROS can serve as a secondary messenger molecule that influences Mitogen-Activated Protein Kinases (MAPK) and NF- $\mathrm{B}$ activity leading to the expression of pro-inflammatory genes thus promoting M1 polarization $[71,72]$. However, ROS have also been implicated in the early stages of M2 polarization and TAM differentiation indicating a complex relationship between ROS and macrophage polarization [73,74]. Another complication involves the dosedependent relationship between irradiation and macrophage polarization. Local radiotherapy can affect the balance between immunosuppression and immune anti-tumor effects 
depending on the dose fractionation, the total dose, and the cancer type.

Higher dose irradiation ( $>10 \mathrm{~Gy}$ ) causes the release of damage-associated molecular patterns (DAMPs) which induce the expression of pro-inflammatory cytokines, chemokines, and effector molecules activating the ceramide pathway which triggers apoptosis via acid sphingomyelinase [75,76]. However, an increase in the number of M2-like TAMs has been observed for in vitro and model murine prostate, oral, and pancreatic cancer when exposed to $>10$ Gy doses of radiotherapy [77-79]. Following the radiation of an in vivo murine oral cancer model, M2 macrophages were polarized from CD11b+ myeloid cells and were associated with tumoral recurrence and accelerated tumoral growth [79]. Lower dose irradiation $(<1 \mathrm{~Gy})$, which serves as a lower toxicity regime in comparison to higher dose irradiation, delivered during a hypofractionation treatment regime has been demonstrated to induce apoptosis of tumoral cells and stromal cells which are efficiently engulfed by macrophages, leading to the clearance of tumoral antigens and the production of anti-inflammatory mediators including TGF- $\beta$ and IL-10. Specifically, lower dose irradiation has been demonstrated to reprogram M1 macrophages towards M2 TAM in both human and murine macrophages in vitro [80]. On the other hand, moderate doses of irradiation (between 1 and 10 Gy) shows a mixed M1/M2 phenotype activation. An interesting study by Prakash et al. demonstrated that irradiation of late-stage insulinoma-bearing mice induced an inflammatory response which was characterized by a decrease in M2 macrophage-associated cytokines and the induction of M1 macrophages. The groups' results were similarly reflected in vitro, where it was noted that the expression of iNOS, NO, $\mathrm{NF}_{\kappa} \mathrm{B}$ pp65, pSTAT3 and pro-inflammatory cytokines were down-regulated [81]. In a glioblastoma murine model treated with moderate doses of irradiation, Leblond, et al. observed a decrease in Mo macrophages concurrent with an increase in M2 TAMs. The group demonstrated that the radiation did not modify the macrophage phenotype but rather that M1 macrophages were more sensitive to ionizing radiation than M2 macrophages in both normoxic and hypoxic environments [82].

Overall, both in vitro and ex vivo studies have demonstrated that single low-dose radiation treatments are associated with anti-inflammatory M2 macrophage activation via the production of iNOS, $\mathrm{NO}$, and $\mathrm{O}_{2}^{-}$which induced the expression of pro-inflammatory cytokines (e.g. IL-1 $\beta$, IL- 6 and $\mathrm{TNF}-\alpha$ ), whilst moderate-dose irradiation enhances the pro-inflammatory properties of both M1 and M2 macrophages $[62,76,81,83]$. Interestingly, although local radiation cannot completely reprogram TAMs, a few studies have demonstrated that a low-to-moderate dose of whole-body irradiation in tumor-bearing mice results in a M1 cytokine expression profile $[81,84-86]$. This type of response has been hypothesized to be due to the mobilization of fresh reprogrammed macrophages to various lymphoid organs to infiltrate the tumor site. Of course, it should be noted, that whole-body irradiation studies have been applied mainly to mice as this radiation regime is not applicable to human patients [65].
Notably, the full molecular mechanisms of exactly how TAMs promote therapeutic resistance is beyond the scope of this mini-review and the authors highly recommend more indepth reviews [87-89].

\section{Role of TAMs in immunotherapy resistance}

Although this mini-review is mainly focused on TAMs resistance to chemo-, hormone- and radiotherapy, the importance of TAMs in other treatment strategies, such as immunotherapies, is also relevant. Immunotherapy strategies are a highly promising approach to cancer treatment. Several immunotherapies have been developed, including immune modulators agents like cytokines (to enhance the immune response), adoptive cell transfer (which includes the chimeric antigen receptor (CAR) T-cell therapy), and monoclonal antibodies therapies (which enable either the direct targeting of cancer cells or the inhibitory molecules known to dampen immune responses) [90]. In the case of monoclonal antibody therapies, several studies have revealed that macrophages may impact treatment efficacies in certain circumstances. For example, the expression of programmed death ligand 1 (PD-L1) by TAMs, and by cancer cells, has been described to inhibit $\mathrm{T}$ cell activation which dampen anti-cancer immune responses and consequently promotes tumor growth [91,92]. Indeed, the interaction between PD-L1 and PD-1, expressed by $\mathrm{T}$ cells, induces $\mathrm{T}$ cell inactivation and decrease proliferation $[93,94]$. The immune checkpoint blockade (ICB) strategy aims to inhibit this PD-L1/PD-1 interaction with monoclonal antibody anti-PD-L1 or anti-PD-1 to avoid T cell inhibition [95,96]. Unfortunately, although this strategy seems efficient for several cancer types, recent evidence has indicated that macrophage-derived granulin dampens CD8+ T cell infiltration into metastatic pancreatic tumors and drives resistance against anti-PD-1 therapy. The inhibition of granulin, produced by macrophages, promotes $\mathrm{CD}^{+} \mathrm{T}$ cell infiltration and enhances ICB therapy [97]. Additionally, macrophages also express the V-Domain Ig Suppressor Of T Cell Activation (VISTA) protein [98]. VISTA shares a homology with PD-L1, and can also play a role in the dampening $\mathrm{T}$ cell activation [99]. The upregulation of VISTA expression by macrophages, after ICB treatment in prostate and melanoma cancer, has been hypothesized to represent a compensatory pathway implicated in ICB resistance [100].

Thus, collectively, these studies indicate the major impact of TAMs on cancer cells and chemo-hormone-,radio- and immunotherapy resistance.

\section{Macrophages targeting therapeutic strategies to im- prove current treatment}

The TME is known to polarize TAMs toward the M2 phenotype and the phenomenon is now commonly associated with a poor prognosis in various cancers. The participation of TAMs in chemo-, immune- and radiotherapy resistance is considered an important aspect of treatment strategies thus the following section will highlight the potential of targeting TAMs. Specifically, strategies to reduce tumor progression and therapy resistance via the re-education of M2 TAMs towards 
the M1 phenotype or the reduction of M2 TAMs to skew the M1/M2 population towards a pro-inflammatory ratio will be discussed.

\section{Specific depletion of pro-tumorigenic TAMs}

Melittin, a major compound of bee venom, has been observed to target pro-tumorigenic M2 TAMs in a Lewis lung carcinoma mouse model, and to reduce the M2 population without affecting pro-inflammatory M1 TAMs [101]. The mechanisms associated with this decrease in M2 TAMs are not currently well known but a decrease of angiogenesis was observed in the tumor stroma of mice injected with melittin. Melittin has also been coupled with other peptides, such as the pro-apoptotic peptide d-(KLAKLAK) $)_{2}$, to target M2 TAMs and induce cell death by mitochondrial-dependent apoptosis thus leading to decreased angiogenesis, tumor growth rates, and tumor weight [102]. The same melittin-d(KLAKLAK) compound has also been associated with enhanced anti-tumor effects of immunotherapy in breast cancer models [103]. Another study demonstrated the specific depletion of $\mathrm{CD}_{163} 3^{+}$ TAMs using CD163 antibodies conjugated with cytotoxic lipid nanoparticles loaded with doxorubicin. The CD163+ TAMs depletion induced an infiltration of activated T cells in tumors thus leading to tumor regression in melanoma mice models [104].

\section{Re-education of TAMs toward anti-tumorigenic macro- phages}

In vitro transcribed messenger RNAs (mRNAs) are a promising new approach to re-educating M2 TAMs toward antitumorigenic M1 macrophages. These synthetic mRNAs enable researchers to transiently translate the proteins of interest and target specific cells. In vitro transcribed mRNA of the Interferon Regulatory Factor (IRF) protein family, specifically IRF5 and IRF5 activating kinase IKK $\beta$ which are highly expressed in M1, have been used to successfully reprogram TAMs in proinflammatory macrophages. The studies demonstrated a lower tumor size in vivo for glioblastoma and melanoma lung metastases in mice $[105,106]$.

Direct injections of IL-21, a type I cytokine mostly produced by T cells and natural killer T cells [107], in tumors also succeeded in reprograming TAMs in anti-tumorigenic M1 phenotype when combined with immunotherapeutic Anti-Her2/neu treatment in breast cancer cells [108]. M2 repolarization toward M1 can also be achieved by combining siRNA targeting IKK $\beta$, a $\mathrm{NF}-\kappa \mathrm{B}$ regulating kinase, as its silencing could lead to $\mathrm{M} 1$ repolarization and STAT6 inhibition to impair IL-4-mediated M2 activation pathway. IKK $\beta$ siRNA and STAT6 inhibitor molecules were combined in a $\mathrm{pH}$-activated micellar nanodrug targeting M2 peptides, designed to only activate in the acidic environment of the TME and not have negative side effects in healthy tissues with a more neutral $\mathrm{pH}$ [109]. The system was able to successfully repolarize M2 to M1 TAMs and suppress tumor growth and metastasis both in vitro and in vivo in murine models whilst minimizing the inflammatory and toxic effects in the liver and lungs. Interestingly, paclitaxel has recently been discovered to induce M2 to M1 reprogramming through TLR4 activation in mice models of breast and melanoma tumors. Paclitaxel exposure blocked IL-4/STAT6-mediated M2 activation and led to increased $\mathrm{NF}-\kappa \mathrm{B}$ activation, repolarizing TAMs to M1 phenotype expressing markers such as TNF- $\alpha$ and IL-12 [110].

Di Mitri, et al. have demonstrated that prostate tumors with no expression of tumor suppressor gene PTEN are highly infiltrated with TAMs expressing $\mathrm{C}-\mathrm{X}-\mathrm{C}$ Chemokine Receptor Type 2 (CXCR2), which leads to M2 pro-tumoral phenotype when activated with its ligand CXCL2. They established that these tumors were sensitive to treatment by a CXCR2 antagonist which induced TAMs re-education towards M1 anti-tumoral phenotype and therefore tumor inhibition. The authors also suggested combining treatment with a CXCR2 antagonist with infusions of CXCR2-KO activated monocytes, which showed similar results as CXCR2 treatment in their prostate cancer mice models, to further increase the efficacity on tumor inhibition [111]. M1 to M2 re-education could also be achieved by incubating isolated peritoneal macrophages with various polysaccharides, for example from common buckwheat or guava seeds. Incubated macrophages showed elevated expressions of M1 cytokines such as IL- 6 and TNF- $\alpha$ in a dose dependent way. Treatment of MCF7 breast cancer cells with the supernatant of polysaccharides polarized macrophages culture medium induced a decreased MCF7 cell growth [112].

Radiotherapy also exhibited the ability to induce M2 to M1 repolarization. Irradiation of ex vivo colorectal cancer tissue samples revealed an increased expression of M1 markers in flow cytometry indicating increased M1/M2 ratio, which was also observed after irradiation of cancer cells in 3D co-cultures with macrophages. This M2 to M1 shift could be at least partly achieved with the help of cancer cells exosomes. Indeed, co-cultures of macrophages and exosomes harvested from irradiated cancer cell lines led to M1 polarization compared to co-cultures of macrophages and exosomes from non-irradiated cancer cell lines [113].

\section{Other therapeutic strategies with macrophages targe- ting}

A few other therapeutic strategies have also been developed for macrophage targeting, although interestingly their aim is not to impact M1/M2 ratio unlike the previous strategies, but rather to prevent tumors from escaping the immune system. As an example, the expression of CD47 cell surface markers by cancer cells is a "don't eat me" signal for macrophages to ignore cancer cells. Immunotherapy using blocking antibodies against CD47 has been shown to reinduce cancer cells phagocytosis by macrophages in vitro and total cancer eradication in acute myeloid leukemia patient-derived xenograft mice models. Preclinical studies are currently ongoing with CD47 antibodies such as magrolimab, in combination with other cancer treatments like azacytidine [114,115].

Macrophages targeted for cancer treatment can enable the recruitment of other cells to the tumor such as $\mathrm{T}$ cells. TAMs 
secrete anti-inflammatory proteins and cytokines to create an immunosuppressive environment thus avoiding the recruitment of $\mathrm{T}$ cells which could participate in tumor clearance. Kaneda, et al. showed that phosphoinositide 3-kinase gamma ( $\mathrm{PI} 3 \mathrm{~K} \gamma$ ) can act as a switch between immune suppression and immune stimulation, as $\mathrm{PI} 3 \mathrm{~K} \gamma$ expression inhibits $\mathrm{NF}-\kappa \mathrm{B}$ and activates CCAAT-Enhancer-Binding Proteins (C/EBP), leading to immune suppression and tumor growth. Molecules specifically inhibiting $\mathrm{PI} 3 \mathrm{~K} \gamma$ expression in macrophages will inhibit $\mathrm{C} /$ EBP $\beta$ and stimulate $\mathrm{NF}-\kappa \mathrm{B}$ activation, thus allowing an immunostimulatory transcriptional program to restore CD8+ T cell activation and cytotoxic activity, leading to tumor growth inhibition and extended survival in mouse models [116].

\section{Conclusion}

Whilst M2 macrophages induce tumor cell proliferation and angiogenesis driving metastatic dissemination and tumoral growth, M1 macrophages promote an anti-tumor immune response. Thus, the accumulation of TAMs with an M2 antiinflammatory phenotype in tumor tissue is associated with poor patient outcomes for several tumor types. Recent studies have demonstrated that TAMs produce exosomes enriched with miRNAs able to confer resistance to chemotherapeutics, including cisplatin and $5-\mathrm{FU}$. The $\mathrm{NF}-\kappa \mathrm{B}$ pathway has also been indicated as a possible mechanism of chemotherapeutic resistance to paclitaxel. Other treatment options, such as local radiotherapy, can affect the balance between immunosuppression and immune anti-tumor effects depending on dose fractionation, total dose, and the cancer type. After a high dose of radiation an increase in the number of M2-like TAMs has been observed for in vitro and model murine prostate, oral, and pancreatic cancer. In lower doses, irradiation has been demonstrated to reprogram M1 macrophages towards M2 TAM in both human and murine macrophages in vitro. Conversely, moderate doses of radiation show mixed M1/M2 activation wherein the destruction in Mo macrophages could explain the increase in the M2 macrophage population. To combat these issues of treatment resistance, research has been orientated towards the reduction and re-education of TAMs. Depletion has been achieved via melittin, pro-apoptotic peptides, and cytotoxic lipid nanoparticles, whilst re-education induction has found success in using mRNAs, siRNAs in $\mathrm{pH}$-sensitive nanodrugs, and polysaccharides derived from buckwheat and guava seeds. Other strategies also include the blocking of CD47 "don't eat me" signals of cancer cells and using PI3K as an immune stimulatory switch. Overall, recent research demonstrates that M2 TAMs - and the balance between M1/ M2 macrophages in tumoral tissue - have a profound effect on cancer response to treatment, and the subsequent rise in resistance, and must be addressed to provide effective anticancer therapies.

\section{Acknowledgements}

We would like to thank our financial support; the Ligue Contre le Cancer, the Université de Lorraine and, particularly, the LUE program and CNRS, France.

\section{References}

1. Liao HF, Yang YC, Chen YY, Hsu ML, Shieh HR, et al. (2007) Macrophages derived from bone marrow modulate differentiation of myeloid dendritic cells. Cell Mol Life Sci 64: 104-111. Link: https://bit.ly/2Qk1fhS

2. Zhang $X$, Mosser D (2008) Macrophage activation by endogenous danger signals. J Pathol 214: 161-178. Link: https://bit.ly/3w0cN94

3. Bertani FR, Mozetic P, Fioramonti M, luliani M, Ribelli G, et al. (2017) Classification of M1/M2-polarized human macrophages by label-free hyperspectral reflectance confocal microscopy and multivariate analysis. Sci Rep 7: 8965. Link: https://bit.ly/3fkFeli

4. Martinez FO, Gordon S (2014) The M1 and M2 paradigm of macrophage activation: time for reassessment. F1000Prime Rep 6. Link: https://bit.ly/3w6Ycc7

5. Rostam HM, Reynolds PM, Alexander MR, Gadegaard N, Ghaemmaghami AM (2017) Image based Machine Learning for identification of macrophage subsets. Sci Rep 7: 3521. Link: https://go.nature.com/3hntK9i

6. Muraille $\mathrm{E}$, Leo $\mathrm{O}$, Moser M (2014) $\mathrm{TH} 1 / \mathrm{TH} 2$ paradigm extended: macrophage polarization as an unappreciated pathogen-driven escape mechanism? Front Immunol 5: 603. Link: https://bit.ly/3fgrFJE

7. Ait-Lounis A, Laraba-Djebari F (2015) TNF-alpha modulates adipose macrophage polarization to M1 phenotype in response to scorpion venom Inflamm Res 64: 929-936. Link: https://bit.ly/3y96uBN

8. Lam RS, O'Brien-Simpson NM, Holden JA, Lenzo JC, Fong SB, et al. (2016) Unprimed, M1 and M2 Macrophages Differentially Interact with Porphyromonas gingivalis. PLoS ONE 11: e0158629. Link: https://bit.ly/3ffoguH

9. Lu CH, Lai CY, Yeh LD, Liu YL, Su YW, et al. (2018) Involvement of M1 Macrophage Polarization in Endosomal Toll-Like Receptors Activated Psoriatic Inflammation. Mediators of Inflammation 1-14. Link: https://bit.ly/2RTqJml

10. Zhao Y, Tian PX, Han F, Zheng J, Xia XX, et al. (2017) Comparison of the characteristics of macrophages derived from murine spleen, peritoneal cavity, and bone marrow. J Zhejiang Univ Sci B 18: 1055-1063. Link: https://bit.ly/3hjue0g

11. van Dale F, van Stevendaal M, Fennemann F, Verdoes M, llina O (2018) Molecular Repolarisation of Tumour-Associated Macrophages. Molecules 24 9. Link: https://bit.ly/3oo6gmd

12. Genard G, Lucas S, Michiels C (2017) Reprogramming of Tumor-Associated Macrophages with Anticancer Therapies: Radiotherapy versus Chemo- and Immunotherapies. Front Immunol 8: 828. Link: https://bit.ly/3hrzi2D

13. Mantovani A, Biswas SK, Galdiero MR, Sica A, Locati M (2013) Macrophage plasticity and polarization in tissue repair and remodelling: Macrophage plasticity and polarization in tissue repair and remodelling. J Pathol 229: 176 185. Link: https://bit.ly/33E4gMT

14. Huang F, Zhao JL, Wang L, Gao CC, Liang SQ, et al. (2017) miR-148a-3p Mediates Notch Signaling to Promote the Differentiation and M1 Activation of Macrophages. Front Immunol 8: 1327. Link: https://bit.ly/3y9TX1h

15. Mantovani A, Schioppa T, Porta C, Allaven P, Sica A (2006) Role of tumorassociated macrophages in tumor progression and invasion. Cancer Metastasis Rev 25: 315-322. Link: https://bit.ly/3bnvHit

16. Yang Q, Guo N, Zhou Y, Chen J, Wei Q, et al. (2020) The role of tumorassociated macrophages (TAMs) in tumor progression and relevant advance in targeted therapy. Acta Pharmaceutica Sinica B 10: 2156-2170. Link: https://bit.ly/3y9u5hh

17. Zhang B, Zhang Y, Yao G, Gao J, Yang B, et al. (2012) M2-polarized macrophages promote metastatic behavior of Lewis lung carcinoma cells by 
inducing vascular endothelial growth factor-C expression. Clinics 67: 901-906 Link: https://bit.ly/2RN4ZIX

18. Hu H, Hang JJ, Han T, Zhuo M, Jiao F, et al. (2016) The M2 phenotype of tumor-associated macrophages in the stroma confers a poor prognosis in pancreatic cancer. Tumour Biol 37: 8657-8664. Link: https://bit.ly/3hoEmF0

19. Lan C, Huang X, Lin S, Huang H, Cai Q, et al. (2013) Expression of M2 Polarized Macrophages is Associated with Poor Prognosis for Advanced Epithelial Ovarian Cancer. Technol Cancer Res Treat 12: 259-267. Link https://bit.ly/3uL1fpR

20. Zhu S, Luo Z, Li X, Han X, Shi S, et al. (2021) Tumor-associated macrophages: role in tumorigenesis and immunotherapy implications. $J$ Cancer 12: 54-64 Link: https://bit.ly/3hnA40g

21. Cheng H, Wang Z, Fu L, Xu T (2019) Macrophage Polarization in the Development and Progression of Ovarian Cancers: An Overview. Front Oncol 9: 421. Link: https://bit.ly/2SQAxOR

22. Mu X, Shi W, Xu Y, Xu C, Zhao T, et al. (2018) Tumor-derived lactate induces M2 macrophage polarization via the activation of the ERK/STAT3 signaling pathway in breast cancer. Cell Cycle 17: 428-438. Link: https://bit.ly/3oeGhgB

23. Huang CY, Ye ZH, Huang MY, Lu JJ (2020) Regulation of CD47 expression in cancer cells. Transl Oncol 13: 100862. Link: https://bit.ly/33Hv6DM

24. Andaloussi EL, Mäger S, Breakefield I, Wood MJA (2013) Extracellular vesicles: biology and emerging therapeutic opportunities. Nat Rev Drug Discov 12 347-357. Link: https://bit.ly/2SNEP9B

25. Yao ZY, Chen WB, Shao SS, Ma SZ, Yang CB, et al. (2019) Role of exosomeassociated microRNA in diagnostic and therapeutic applications to metabolic disorders. J Zhejiang Univ Sci B 19: 183-198. Link: https://bit.ly/2RJkGRr

26. Chen X, Ying X, Wang X, Wu X, Zhu Q, et al. (2017) Exosomes derived from hypoxic epithelial ovarian cancer deliver microRNA-940 to induce macrophage M2 polarization. Oncol Rep 38: 522-528. Link: https://bit.ly/3bpC4BF

27. Wang X, Luo G, Zhang K, Cao J, Huang C, et al. (2018) Hypoxic Tumor-Derived Exosomal miR-301a Mediates M2 Macrophage Polarization via PTEN/PI3Ky to Promote Pancreatic Cancer Metastasis. Cancer Res 78: 4586-4598. Link: https://bit.ly/3oaRrmG

28. Chen C, Liu JM, Luo YP (2020) MicroRNAs in tumor immunity: functional regulation in tumor-associated macrophages. J Zhejiang Univ Sci B 21: $12-$ 28. Link: https://bit.ly/3y6GVkR

29. Ying $X$, Wu Q, Wu X, Zhu Q, Wang $X$, et al. (2016) Epithelial ovarian cancer secreted exosomal miR-222-3p induces polarization of tumor-associated macrophages. Oncotarget 7: 43076-43087. Link: https://bit.ly/3w3vJE4

30. Wilson HM (2014) SOCS Proteins in Macrophage Polarization and Function Front Immunol 5: 357. Link: https://bit.ly/3ya7MfS

31. Cooks T, Pateras IS, Jenkins LM, Patel KM, Robles Al, et al. (2018) Mutant p53 cancers reprogram macrophages to tumor supporting macrophages via exosomal miR-1246. Nat Commun 9: 771. Link: https://bit.ly/3w15den

32. Zhao X, Qu J, Sun Y, Wang J, Liu X, et al. (2017) Prognostic significance of tumor-associated macrophages in breast cancer: A meta-analysis of the literature. Oncotarget 8: 30576-30586. Link: https://bit.ly/2QeEoUR

33. Jayasingam SD, Citartan M, Thang TH, Mat Zin AA, Ang KC, et al. (2020) Evaluating the Polarization of Tumor-Associated Macrophages Into M1 and M2 Phenotypes in Human Cancer Tissue: Technicalities and Challenges in Routine Clinical Practice. Front Oncol 9: 1512. Link: https://bit.ly/3bjGXMA

34. Yuan X, Zhang J, Li D, Mao Y, Mo F, et al. (2017) Prognostic significance of tumor-associated macrophages in ovarian cancer: A meta-analysis. Gynecol Oncol 147: 181-187. Link: https://bit.ly/2SDRPOQ

35. Fujimura T, Kambayashi Y, Fujisawa Y, Hidaka T, Aiba S (2018) Tumor associated macrophages: Therapeutic targets for skin cancer. Front Oncol 8 : 3. Link: https://bit.ly/2RM7rzq

36. Kumar AT, Knops A, Swendseid B, Martinez-Outschoom U, Harshyne L,et al. (2019) Prognostic Significance of Tumor-Associated Macrophage Content in Head and Neck Squamous Cell Carcinoma: A Meta-Analysis. Front Oncol 9 . 656. Link: Link: https://bit.ly/3hlVjzS

37. Ding W, Tan Y, Qian Y, Xue W, Wang Y, et al. (2019) Clinicopathologic and prognostic significance of tumor-associated macrophages in patients with hepatocellular carcinoma: A meta-analysis. PLoS One 14: e0223971. Link: https://bit.ly/3w5DFV0

38. Wang XL, Jiang JT, Wu CP (2016) Prognostic significance of tumor-associated macrophage infiltration in gastric cancer: a meta-analysis. Genet Mol Res 15 15049040. Link: Link: https://bit.ly/2QgppK4

39. Yin S, Huang J, Li Z, Zhang J, Luo J, et al. (2017) The Prognostic and Clinicopathological Significance of Tumor-Associated Macrophages in Patients with Gastric Cancer: A Meta-Analysis. PLoS One 12: e0170042. Link: https://bit.ly/3uJQLYO

40. Yu M, Guan R, Hong W, Zhou Y, Lin Y, et al. (2019) Prognostic value of tumorassociated macrophages in pancreatic cancer: A meta-analysis. Cancer Manag Res 11: 4041-4058. Link: https://bit.ly/3ulD4IV

41. Boström MM, Irjala H, Mirtti T, Taimen P, Kauko T, et al. (2015) TumorAssociated Macrophages Provide Significant Prognostic Information in Urothelial Bladder Cancer. PLoS One 10: e0133552. Link: https://bit ly/3y9y5TG

42. Soo RA, Chen Z, Yan Teng RS, Tan HL, lacopetta B, et al. (2018) Prognostic significance of immune cells in non-small cell lung cancer: Meta-analysis. Oncotarget 9: 24801-24820. Link: https://bit.ly/2SDSAaE

43. Zhu X, Shen $H$, Yin X, Yang M, Wei $H$, et al. (2019) Macrophages derived exosomes deliver miR-223 to epithelial ovarian cancer cells to elicit a chemoresistant phenotype. J Exp Clin Cancer Res 38: 81. Link: Link: https:// bit.ly/3blw2Ss

44. Yin $Y$, Yao S, Hu Y, Feng Y, Li M, et al. (2017) The Immune-microenvironment Confers Chemoresistance of Colorectal Cancer through Macrophage-Derived IL6. Clin Cancer Res 23: 7375-7387. Link: https://bit.ly/3eK6nFr

45. Bao W, Wang HH, Tian FJ, He XY, Qiu MT, et al. (2013) A TrkB-STAT3-miR204-5p regulatory circuitry controls proliferation and invasion of endometrial carcinoma cells. Mol Cancer 12: 155. Link: https://bit.ly/3oaTB5M

46. Courboulin A, Paulin R, Giguère NJ, Saksouk N, Perreault T, et al. (2011) Role for miR-204 in human pulmonary arterial hypertension. J Exp Med 208: 535548. Link: https://bit.ly/3tGv0ag

47. Bian Z, Jin L, Zhang J, Yin Y, Quan C, et al. (2016) LncRNA-UCA1 enhances cell proliferation and 5 -fluorouracil resistance in colorectal cancer by inhibiting miR-204-5p. Sci Rep 6: 23892. Link: https://bit.ly/3tJd0ft

48. Yin Y, Zhang B, Wang W, Fei B, Quan C, et al. (2014) miR-204-5p Inhibits Proliferation and Invasion and Enhances Chemotherapeutic Sensitivity of Colorectal Cancer Cells by Downregulating RAB22A. Clin Cancer Res 20: 61876199. Link: https://bit.ly/3tCMG6w

49. Zhu X, Shen H, Yin X, Long L, Chen X, et al. (2017) IL-6R/STAT3/miR-204 feedback loop contributes to cisplatin resistance of epithelial ovarian cancer cells. Oncotarget 8: 39154-39166. Link: https://bit.ly/2SLu5bM

50. Xu X, Ye J, Huang C, Yan Y, Li J (2019) M2 macrophage-derived IL6 mediates resistance of breast cancer cells to hedgehog inhibition. Toxicol Appl Pharmacol 364: 77-82. Link: https://bit.ly/2RSTtM0

51. Ruffell B, Chang-Strachan D, Chan V, Rosenbusch A, Ho CM, et al. (2014) Macrophage IL-10 blocks CD8+ T cell-dependent responses to chemotherapy by suppressing IL-12 expression in intratumoral dendritic cells. Cancer Cell 26 623-637. Link: https://bit.ly/2RKE6p4 
52. Wei C, Yang C, Wang S, Shi D, Zhang C, et al. (2019) M2 macrophages confer resistance to 5-fluorouracil in colorectal cancer through the activation of CCL22/PI3K/AKT signaling. OTT 12: 3051-3063. Link: https://bit.ly/3uKZGZg

53. Li D, Ji H, Niu X, Yin L, Wang Y, et al. (2020) Tumor-associated macrophages secrete CC-chemokine ligand 2 and induce tamoxifen resistance by activating PI3K/Akt/mTOR in breast cancer. Cancer Sci 111: 47-58. Link: https://bit.ly/2RjdOu2

54. Castellaro AM, Rodriguez-Baili MC, Di Tada CE, Gil GA (2019) TumorAssociated Macrophages Induce Endocrine Therapy Resistance in ER+ Breast Cancer Cells. Cancers 11: 189. Link: https://bit.ly/3tD0JsM

55. Olson OC, Kim H, Quail DF, Foley EA, Joyce JA (2017) Tumor-Associated Macrophages Suppress the Cytotoxic Activity of Antimitotic Agents. Cell Reports 19: 101-113. Link: https://bit.ly/3y9Kil0

56. Halbrook CJ, Pontious C, Kovalenko I, Lapienyte L, Dreyer S, et al. (2019) Macrophage-Released Pyrimidines Inhibit Gemcitabine Therapy in Pancreatic Cancer. Cell Metab 29: 1390-1399.e6. Link: https://bit.ly/3uLfZoL

57. Plunkett W, Huang P, Xu YZ, Heinemann V, Grunewald R, et al. (1995) Gemcitabine: metabolism, mechanisms of action, and self-potentiation. Semin Oncol 22: 3-10. Link: https://bit.ly/3uLKAm2

58. Golden EB, Apetoh L (2015) Radiotherapy and Immunogenic Cell Death. Semin Radiat Oncol 25: 11-17. Link: https://bit.ly/3uJzazb

59. Barker HE, Paget JTE, Khan AA, Harrington KJ (2015) The tumou microenvironment after radiotherapy: mechanisms of resistance and recurrence. Nat Rev Cancer 15: 409-425. Link: https://bit.ly/3fixZAe

60. Carvalho H, Villar R (2018) Radiotherapy and immune response: the systemic effects of a local treatment. Clinics 73. Link: https://bit.ly/3obqSh8

61. Mantovani A, Allavena P (2015) The interaction of anticancer therapies with tumor-associated macrophages. J Exp Med 212: 435-445. Link: https://bit.ly/3hAtAvF

62. Teresa Pinto A, Laranjeiro Pinto M, Patrícia Cardoso A, Monteiro C, Teixeira Pinto $M$, et al. (2016) lonizing radiation modulates human macrophages towards a pro-inflammatory phenotype preserving their pro-invasive and proangiogenic capacities. Sci Rep 6: 18765. Link: https://bit.ly/3hnArs3

63. Hildebrandt MP, Seed CN, Freema G (1998) Mechanisms of the antiinflammatory activity of low-dose radiation therapy. International Journal of Radiation Biology 74: 367-378. Link: https://bit.ly/3fiybPY

64. Lindström A, Midtbö K, Arnesson LG, Garvin S, Shabo I (2017) Fusion between M2-macrophages and cancer cells results in a subpopulation of radioresistant cells with enhanced DNA-repair capacity. Oncotarget 8: 51370-51386. Link: https://bit.ly/3eJKwOs

65. Crittenden MR, Cottam B, Savage T, Nguyen C, Newell P, et al. (2012) Expression of NF-KB p50 in Tumor Stroma Limits the Control of Tumors by Radiation Therapy. PLoS ONE 7: e39295. Link: https://bit.ly/3tE9KIf

66. Brown JM, Recht L, Strober S (2017) The Promise of Targeting Macrophages in Cancer Therapy. Clin Cancer Res 23: 3241-3250. Link: https://bit.ly/3bpggpL

67. Demaria S, Ng B, Devitt ML, Babb JS, Kawashima N, et al. (2004) lonizing radiation inhibition of distant untreated tumors (abscopal effect) is immune mediated. Int $\mathrm{J}$ Radiat Oncol Biol Phys . 58: 862-870. Link: https://bit.ly/3elskV9

68. Hildebrandt G, Loppnow G, Jahns J, Hindemith M, Anderegg U, et al. (2003) Inhibition of the iNOS Pathway in Inflammatory Macrophages by Low-Dose X-Irradiation In Vitro: Is There a Time Dependence? Strahlenther Onkol 179. 158-166. Link: https://bit.ly/33EnXUR

69. McKinney LC, Aquilla EM, Coffin D, Wink DA, Vodovotz Y (1998) lonizing radiation potentiates the induction of nitric oxide synthase by IFN- $\gamma$ and/or LPS in murine macrophage cell lines: role of TNF-a. J Leukoc Biol 64: 459466. Link: https://bit.ly/3eKzWGW
70. Jeong H, Kim S, Hong BJ, Lee CJ, Kim YE, et al. (2019) Tumor-associated macrophages enhance tumor hypoxia and aerobic glycolysis. Cancer Res 79 795-806. Link: https://bit.ly/3ocDrJ0

71. Wang N, Liang H, Zen K (2014) Molecular Mechanisms That Influence the Macrophage M1â€"M2 Polarization Balance. Front Immunol 5. Link: https://bit.ly/33FY3Q

72. Galván-Peña S, O’Neill LA (2014) Metabolic Reprograming in Macrophage Polarization. Front Immunol 5. Link: https://bit.ly/3uNola3

73. Griess B, Mir S, Datta K, Teoh-Fitzgerald M (2020) Scavenging reactive oxygen species selectively inhibits M2 macrophage polarization and their protumorigenic function in part, via Stat3 suppression. Free Radic Biol Med 147: 48-60. Link: https://bit.ly/3ocvwLW

74. Zhang Y, Choksi S, Chen K, Pobezinskaya Y, Linnoila I, et al. (2013) ROS play a critical role in the differentiation of alternatively activated macrophages and the occurrence of tumor-associated macrophages. Cell Res 23: 898-914. Link: https://bit.ly/3uJAuSF

75. Garcia-Barros M, Paris F, Cordon-Cardo C, Lyden D, Rafii S (2003) Tumor Response to Radiotherapy Regulated by Endothelial Cell Apoptosis. Science 300: 1155-1159. Link: https://bit.ly/3y6Qalg

76. Gough MJ, Young K, Crittenden M (2013) The Impact of the Myeloid Response to Radiation Therapy. Clin Dev Immunol 2013: 281958. Link: https://bit.ly/3tJuU1A

77. Seifert L, Werba G , Tiwari S, Giao Ly NN , Nguy S, et al. (2016) Radiation Therapy Induces Macrophages to Suppress T-Cell Responses Against Pancreatic Tumors in Mice. Gastroenterology 150: 1659-1672.e5. Link: https://bit.ly/2QgHdoo

78. Tsai CS, Chen FH, Wang CC, Huang HL, Jung SMet al. (2007) Macrophages From Irradiated Tumors Express Higher Levels of iNOS, Arginase-I and COX-2, and Promote Tumor Growth. Int J Radiat Oncol Biol Phys 68: 499-507. Link: https://bit.ly/2RNoJw3

79. Okubo M, Kioi M, Nakashima H, Sugiura K, Mitsudo $K$, et al. (2016) M2 polarized macrophages contribute to neovasculogenesis, leading to relapse of oral cancer following radiation. Sci Rep 6: 27548. Link: https://bit.ly/3fagvpQ

80. Frey B, Hehlgans S, Rödel F, Gaipl US (2015) Modulation of inflammation by low and high doses of ionizing radiation: Implications for benign and malign diseases. Cancer Lett 368: 230-237. Link: https://bit.ly/3y9pf8b

81. Prakash H, Klug F, Nadella V, Mazumdar V, Schmitz-Winnenthal H, et al. (2016) Low doses of gamma irradiation potentially modifies immunosuppressive tumor microenvironment by retuning tumor-associated macrophages: lesson from insulinoma. CARCIN 37: 301-313. Link: https://bit.ly/3vXkNYg

82. Leblond MM, Pérès EA, Helaine $C$, Gérault AN, Moulin D, et al. (2017) M2 macrophages are more resistant than $\mathrm{M} 1$ macrophages following radiation therapy in the context of glioblastoma. Oncotarget 8: 72597-72612. Link https://bit.ly/2R6g9IZ

83. Wu Q, Allouch A, Paoletti A, Leteur C, Mirjolet C, et al. (2017) NOX2-dependent ATM kinase activation dictates pro-inflammatory macrophage phenotype and improves effectiveness to radiation therapy. Cell Death Differ 24: 1632-1644. Link: https://bit.ly/3y5CV4d

84. Nowosielska EM, Cheda A, Wrembel-Wargocka J, Janiak MK (2012) Effect of Low Doses of Low-Let Radiation on the Innate Anti-Tumor Reactions in Radioresistant and Radiosensitive Mice. Dose-Response 10: 500-515. Link: https://bit.ly/3odZcsf

85. Song KH, Kim MH, Kang SM, Jung SY, Ahn J, et al. (2015) Analysis of immune cell populations and cytokine profiles in murine splenocytes exposed to whole-body low-dose irradiation. Int J Radiat Biol 91: 795-803. Link: https://bit.ly/33DunU2 
86. Klug F, Prakash H, Huber PE, Seibel T, Bender N , et al. (2013) Low-Dose Irradiation Programs Macrophage Differentiation to an iNOS+/M1 Phenotype that Orchestrates Effective T Cell Immunotherapy. Cancer Cell 24: 589-602. Link: https://bit.ly/3f9e9ri

87. Mantovani A, Marchesi F, Malesci A, Laghi L, Allavena P (2017) Tumourassociated macrophages as treatment targets in oncology. Nat Rev Clin Oncol 14: 399-416. Link: https://bit.ly/3ffGWKP

88. Pathria P, Louis TL, Varner JA (2019) Targeting Tumor-Associated Macrophages in Cancer. Trends Immunol 40: 310-327. Link: https://bit. ly/3odHDIB

89. Sica A, Saccani A, Mantovani A (2002) Tumor-associated macrophages: a molecular perspective. Int Immunopharmacol 2: 1045-1054. Link: Link: https://bit.ly/3tLiEgZ

90. Oiseth SJ, Aziz MS (2017) Cancer immunotherapy: a brief review of the history, possibilities, and challenges ahead. JCMT 3: 250. Link:

91. Qu QX, Huang Q, Shen Y, Zhu YB, Zhang XG (2016) The increase of circulating PD-L1-expressing CD68+ macrophage in ovarian cancer. Tumor Biol 37: 5031-5037. Link: https://bit.ly/2RPvAoK

92. Kuang DM, Zhao Q, Peng C, Xu J, Zhang JP, et al. (2009) Activated monocytes in peritumoral stroma of hepatocellular carcinoma foster immune privilege and disease progression through PD-L1. J Exp Med 206: 1327-1337. Link: https://bit.ly/2QgJno0

93. Shi L, Chen S, Yang L, Li Y (2013) The role of PD-1 and PD-L1 in T-cell immune suppression in patients with hematological malignancies. J Hematol Oncol 6 : 74. Link: https://bit.ly/3bn32tL

94. Yang W, Chen PW, Li H, Alizadeh H, Niederkorn JY (2008) PD-L1: PD-1 Interaction Contributes to the Functional Suppression of T-Cell Responses to Human Uveal Melanoma Cells In Vitro. Invest Ophthalmol Vis Sci 49: 2518 2525. Link: https://bit.ly/2Rj3I1L

95. Makuku R, Khalili N, Razi S, Keshavarz-Fathi M, Rezaei N (2021) Current and Future Perspectives of PD-1/PDL-1 Blockade in Cancer Immunotherapy. J Immunol Res 2021: 6661406. Link: https://bit.ly/3eFkU50

96. Roberts A, Bentley L, Tang T, Stewart F, Pallini C, et al. (2021) Ex vivo modelling of PD-1/PD-L1 immune checkpoint blockade under acute, chronic, and exhaustion-like conditions of T-cell stimulation. Sci Rep 11: 4030. Link: https://bit.ly/3y9qV1t

97. Quaranta V, Rainer C, Nielsen SR, Raymant ML, Ahmed MS, et al. (2018) Macrophage-Derived Granulin Drives Resistance to Immune Checkpoint Inhibition in Metastatic Pancreatic Cancer. Cancer Res 78: 4253-4269. Link: https://bit.ly/3y1bybs

98. Wang L, Rubinstein R, Lines JL, Wasiuk A, Ahonen C, et al. (2011) VISTA, novel mouse Ig superfamily ligand that negatively regulates $T$ cell responses. J Exp Med 208: 577-592. Link: https://bit.ly/3eJODKo

99. Lines JL, Pantazi E, Mak J Wang L, Sempere LF, et al. (2014) VISTA is an immune checkpoint molecule for human T cells. Cancer Res 74: 1924-1932. Link: https://bit.ly/3tluzfq

100. Gao J, Ward JF, Pettaway CA, Shi LZ, Subudhi SK, et al. (2017) VISTA is an inhibitory immune checkpoint that is increased after ipilimumab therapy in patients with prostate cancer. Nat Med 23: 551-555. Link: https://bit. ly/3fcOfEY

101. Lee C, Bae SJS, Joo H, Bae H (2017) Melittin suppresses tumor progression by regulating tumor-associated macrophages in a Lewis lung carcinoma mouse model. Oncotarget 8: 54951-54965. Link: https://bit.ly/3tPggWl
102. Lee C, Jeong H, Bae $Y$, Shin $K$, Kang S, et al. (2019) Targeting of M2-like tumor-associated macrophages with a melittin-based pro-apoptotic peptide. J Immunother Cancer 7: 147. Link: https://bit.ly/33FsKFK

103. Lee H, Kim SY, Choi I (2020) Depletion of tumor-associated macrophages by melittin-dKLA enhances anti PD-L1 mediated anti-tumor effects in breast cancer models. J Immunol 204: 164. Link: https://bit.ly/3ybdnmb

104. Etzerodt A, Tsalkitzi K, Maniecki M, Damsky W, Delfini M, et al. (2019) Specific targeting of CD163+ TAMs mobilizes inflammatory monocytes and promotes T cell-mediated tumor regression. J Exp Med 216: 2394-2411. Link: https://bit.ly/33FQhWY

105. Krausgruber T, Blazek K, Smallie T, Alzabin S, Lockstone H, et al. (2011) IRF5 promotes inflammatory macrophage polarization and $\mathrm{TH} 1-\mathrm{TH} 17$ responses. Nat Immunol 12: 231-238. Link: https://bit.ly/3hkl03J

106. Zhang F, Parayath NN, Ene Cl, Stephan SB, Koehne AL, et al. (2019) Genetic programming of macrophages to perform anti-tumor functions using targeted mRNA nanocarriers. Nat Commun 10: 3974. Link: https:// go.nature.com/3fd75da

107. Leonard WJ, Wan CK (2016) IL-21 Signaling in Immunity. F1000Res 5. Link https://bit.ly/2RNyydB

108. Xu M, Liu M, Du X, Li S, Li H, et al. (2015) Intratumoral Delivery of IL-21 Overcomes Anti-Her2/Neu Resistance through Shifting Tumor-Associated Macrophages from M2 to M1 Phenotype. J Immunol 194: 4997-5006. Link: https://bit.ly/3obwqbs

109. Xiao $\mathrm{H}$, et al. (2020) M2-Like Tumor-Associated Macrophage-Targeted Codelivery of STAT6 Inhibitor and IKKB siRNA Induces M2-to-M Repolarization for Cancer Immunotherapy with Low Immune Side Effects. ACS Cent Sci 6: 1208-1222. Link:

110. Wanderley CW, Guo Y, Li B, Li X, Wang Y, et al. (2018) Paclitaxel reduces tumor growth by reprogramming tumor-associated macrophages to an M1profile in a TLR4-dependent manner. Cancer Res canres 3480.

111. Di Mitri D, Mirenda M, Vasilevska J, Calcinotto A, Delaleu N, et al. (2019) Re-education of Tumor-Associated Macrophages by CXCR2 Blockade Drives Senescence and Tumor Inhibition in Advanced Prostate Cancer. Cell Reports 28: 2156-2168.e5. Link: https://bit.ly/3hmdwxe

112. Lin HC, Lin JY (2020) M1 Polarization but Anti-LPS-Induced Inflammation and Anti-MCF-7 Breast Cancer Cell Growth Effects of Five Selected Polysaccharides. Evid Based Complement Alternat Med 1-17. Link: https://bit.ly/3y89mPG

113. Stary V, Unterleuthne D, Wolf B, Beer A, Dolznig D, et al. (2019) Irradiated cancer exosomes promote M1-like polarization of macrophages and enhance their anti-tumoral responses. European Journal of Cancer S32S33. Link: https://bit.ly/3uWxWRD

114. Chao MP, Takimoto $\mathrm{CH}$, Feng DD, McKenna K, Gip P, et al. (2020) Therapeutic Targeting of the Macrophage Immune Checkpoint CD47 in Myeloid Malignancies. Front Oncol 9: 1380. Link: https://bit.ly/3oe2UCb

115. Liu J, Wang L, Zhao F, Tseng S, Narayanan C, et al. (2015) Pre-Clinica Development of a Humanized Anti-CD47 Antibody with Anti-Cancer Therapeutic Potential. PLoS One 10: e0137345. Link: https://bit ly/3eG7hm3

116. Kaneda MM, Ralainirina N, Li H, Leem CJ, Gorjestani S, et al. (2016) PI3Ky is a molecular switch that controls immune suppression. Nature 539: 437 442. Link: https://bit.ly/3bobZD4

Copyright: @ 2021 Harlé G, et al. This is an open-access article distributed under the terms of the Creative Commons Attribution License, which permits unrestricted use distribution, and reproduction in any medium, provided the original author and source are credited. 